\title{
Yoga Therapy on Stress and Depression among Women Undergoing Infertility Treatment
}

\author{
Namitha Josy ${ }^{1 *}$, Anita Nand ${ }^{2}$ and Radha $\mathrm{K}^{2}$ \\ ${ }^{1}$ Department of Obstetrical and Gynecology, All India Institute of Medical Sciences \\ Raipur, India \\ ${ }^{2}$ Department of Nursing Education, Bhopal Memorial Hospital and Research \\ Centre, India \\ *Corresponding Author: Namitha Josy, Department of Obstetrical and Gynecology, \\ All India Institute of Medical Sciences Raipur, India.
}

Received: April 12, 2021

Published: May 19, 2021

(C) All rights are reserved by Namitha Josy., et al.

\begin{abstract}
Background of the Study: Infertility is regarded as a major life crisis that has the potential to threaten the stability of individuals and relationships in a severe way. During recent years, the development and flourishment of assisted reproduction technique (ART) methods has made the parenting possible for a substantial number of infertile couples all over the world. Most researchers have paid attention to the fact that the sexual distress, depression, guilt, anxiety, frustration, emotional distress and marital problems are all associated with infertility. Yoga and meditation can help women in experiencing the challenges of infertility.

Aim of the Study: To assess the effectiveness of yoga therapy on stress and depression among women undergoing infertility treatment.

Research Methodology: An experimental study was done on women undergoing infertility treatment in Bansal, Madhya Pradesh. Sixty patients were randomized into control and experimental groups. The patients were explained about study, after informed written consent, the tools measuring aggression and its correlates were administered.

Tools: Demographic data sheet, Infertility characteristics, Fertility problem inventory and Becks depression scale were used for data collection. Ethical clearance was obtained from Ethics Committee, BMHRC. Yoga therapy was administered to the experimental group after both groups pre test.

Result: Majority of the patients were within the age group of 20-30yrs suffering from primary infertility. The study revealed a significant difference between stress $(p=0.01)$ in experimental $(155.9+/-3.6)$ and control group $(185.0+/-4.7)$ and depression $(p=0.05)$ in experimental $(17.8+/-2.43)$ and control group (31.4 +/- 2.76). The study found a positive association between the levels of stress and depression on age and duration of infertility.

Conclusion: The study concludes that yoga therapy is effective in reducing stress and depression among patients undergoing infertility treatment in various ART centers.

Keywords: Infertility; Yoga; Stress; Depression; Women
\end{abstract}

\section{Abbreviations}

ART: Assisted Reproduction Technique

\section{Introduction}

Motherhood is an art where mother plays a role along with god almighty in the process of giving away a life to someone unlived.
This helps in sustaining the spirit of hope in this materialistic generation. Motherhood is the language of love and a sense of belongingness to care, to live, to protect and to cherish each other. It's the biggest gift of womankind. It also talks of forgiveness, thanks, pain and disappointments. For every child the dearest person close to his/her heart is none other than mother. 
Infertility is the inability to conceive contributed by various factors of both male and female origin. A study regarding the gender differences resulted that a third (30\%) of the factor is caused by male while another third by the female $(30 \%)$ and both together $17 \%$ of the cases. It's seen that the rate of infertility is increasing per year owing to the social and economic standards of the population across the globe. In a recent survey of family stressors, infertility has been ranked one among the greatest stressors along with divorce and death of the spouse. Many researchers have come forward with relation of infertility and grieving process. It's been described as a chronic sorrow in life. Infertility also encloses the concept of 'disenfranchised grief' without having a social recognition. The stress and depression during infertility is triggered by various other factors like birth of others (friends or family member) children, the behaviour of the family members and other major life events.

The couples taking treatment less than one year is more stressful and depressive than the people taking the treatment for more than 2 years. Studies suggest that maximum severity of depression is seen in the third year of infertility treatment compared to couples suffering from infertility for a past duration of 6 years. The major period of stress and depression is between the $1^{\text {st }}$ and $3^{\text {rd }}$ year of infertility treatment. This period is also followed by anxiety, loss of self- confidence, loss of sexual pleasure and maladjustments thus severely decreasing the quality of life. ART methods and its flourishment have made fertility a possible option in recent years. Maximum couples are supported and assisted with these new methods overcoming all the problems like stress and depression. Most of the studies have shown improvement in total quality of life of the couples as a successful treatment outcome. The major ART methods used by the couples are ovulation induction, intra uterine insemination (IUI) and In vitro fertilisation (IVF). All of these methods are stressful but maximum impact is seen in IVF. The cost of the treatments also add to the emotional level of the couples.

In India CAM including all methods like homeopathy, herbal therapy and yoga are inseparable part of Indian health system from ages. Many recent studies have shown positive effects of yoga therapy in reducing stress and depression among infertile women. Researchers has included meditation and yoga especially 'hata' yoga as an adjuvant to the treatment given to the couple. Studies result that most of the samples in experimental group with all these methods have shown an appreciable improvement compared to their counterpart. Various cognitive therapy and behavioural therapy has also shown such improvements. Majority got pregnant within a period of one year. Yoga helps in the relaxation of body, calm mind, reduces the symptoms like depression, stress, anxiety and improves the quality of life. It balances the whole person and maintains a healthy mind. However this scientific area need further researches and studies to support the same. In Indian settings this virgin field of research will explore a novel dimension of scientific nursing research.

\section{Materials and Methods}

The research approach used in the study is True Experimental. Experimental and control groups were identified, intervention was provided to the experimental group. Pre and post tests were collected from both the groups within specific period of time.

\section{Research design}

A pre-test- post-test control group design on the basis of per day randomization (out of the total eligible samples visited the hospital, lottery method was used to classify the group into experimental and control) was chosen for this study. This design is concerned with examination of the effect of independent variable (yoga) on the dependent variable (stress and depression). This essentially consist of manipulation, control and randomization, the characteristics of a true experimental study.

\begin{tabular}{|c|c|c|c|c|}
\hline Group & $\begin{array}{c}\text { Pre- } \\
\text { Test }\end{array}$ & Intervention & $\begin{array}{c}\text { Post - } \\
\text { Test }\end{array}$ \\
\cline { 2 - 5 } & $\begin{array}{c}\text { Experim } \\
\text { ental }\end{array}$ & P1 & $\mathrm{X}$ & $\mathrm{P} 2$ \\
\hline Control & $\mathrm{P} 1$ & - & $\mathrm{P} 2$ \\
\hline
\end{tabular}

P1- pre test

$\mathrm{X}$ - Intervention - yoga therapy

P2- post test

Figure a

Citation: Namitha Josy., et al. "Yoga Therapy on Stress and Depression among Women Undergoing Infertility Treatment". Acta Scientific Women's Health 3.6 (2021): 75-91. 
Aim

To assess the effectiveness of yoga therapy on stress and depression among women undergoing infertility treatment.

\section{Objectives}

The objectives of the study are:

- $\quad$ To compare the pre-test level of stress and depression among women undergoing infertility treatment in experimental and control group.

- $\quad$ To plan and administer yoga therapy among women undergoing infertility treatment in the experimental group.

- To assess the effectiveness of yoga therapy among women undergoing infertility treatment on stress and depression in experimental and control.

- $\quad$ To find out the association between pre-test stress, depression and demographic variables among women undergoing infertility treatment in experimental and control group.

- To find out the association between pretest stress, depression and infertility variables among women undergoing infertility treatment in experimental and control group.

\section{Operational definition}

- $\quad$ Effectiveness: Adequacy of producing the intended or the expected result. In this study refers to the adequacy of producing change in stress and depression level after yoga therapy.

- Yoga therapy: Application of yogic principles with the objective of achieving a particular spiritual, psychological or physiologic goal. In this study it's the application of yogic principles in infertile women principles with the objective of achieving a change in stress and depression level.

- Stress: A state of mental or emotional strain or tension resulting from adverse or demanding needs of life and society. Here it's a state of mental or emotional strain or tension resulting from adverse or demanding needs of infertility and its treatment.

- Depression: A mental condition, characterised by feelings of severe dejection, inadequacy and guilt, often accompanied by lack of energy and disturbance of appetite and sleep. In the study it refers to a mental situation of women suffering from infertility, characterised by feelings of severe dejection, inadequacy and guilt, often accompanied by lack of energy and disturbance of appetite and sleep.
- Women: Human beings who are biologically females. In the study, females within reproductive age group, unable to conceive or sustain a pregnancy to birth and are visiting various infertility clinics.

- Infertility treatment: Treatment aimed at helping a couple conceive and sustain a pregnancy to birth. Here it refers to all ART treatment methods undergoing in the patient.

\section{Research hypotheses}

- H0: There is no significant change in the level of stress and depression between pre and post yoga therapy among women undergoing infertility treatment in experimental and control group at 0.05 level of significance.

- H1: There is significant change in the level of stress and depression between pre and post yoga therapy among women undergoing infertility treatment in experimental and control group at 0.05 level of significance.

- H2: There is significant association between pretest stress, depression and demographic variables of women undergoing infertility treatment in experimental and control group at 0.05 level of significance.

- H4: There is significant association between pretest stress, depression and infertility variables of women undergoing infertility treatment in experimental and control group at 0.05 level of significance.

\section{Delimitation}

The study is delimited to the fertility clinic of Bansal hospital, Bhopal, Madhya Pradesh during the study period from April 2018 to June 2018.

\section{Research setting}

Department of reproductive medicine, Bansal hospital, Bhopal M.P was the platform of the study. The total number of pregnancies achieved per year in the hospital is 1155 , with ART assistance number of patients delivered is - 1002. The number of patients delivered by IVF is 12 and the number of pregnancies is 5. Overall rate of the Pregnancy is 41.66 (2015 Jan - 2016 Dec). In OPD days the outpatient/new cases per day is 25 . Out of 25 new cases the maximum number of people who met the including criteria were approximately 15 - 10 per day. They were equally distributed according to the sampling/randomization into both the groups. 


\section{Population}

Population of this study was the women, diagnosed with infertility, attending the infertility clinic and seeking technological assistance using ART methods for reproduction. The target population was all the women undergoing infertility treatment. The accessible population was the women undergoing treatment at Bansal hospital.

Sample

Among the females attending the clinic, the patients confirmed infertile by the diagnostic procedures were subjected to the inclusion criteria. The patients who met the inclusion criteria were chosen as the samples for the study.

\section{Inclusion criteria}

- Women undergoing infertility treatment (Ovulation Induction, Intrauterine Insemination and IVF) in Bansal Hospital, Bhopal.

- Who are willing to participate and willing to do yoga in the study.

- Women who are able to read and write Hindi or English.

\section{Exclusion criteria}

- Were already exposed to relaxation techniques

- Had undergone counseling previously

- Had practiced yoga already

- Women who didn't understand Hindi/English.

Sampling technique

Sample in the present study were selected by probability sampling specifically simple random sampling technique (per day randomization). Per day 10 samples were recruited, 5 each in both the control and experimental groups. Per day randomization was done from the samples, who were willing to attend the class on Saturdays and were listed down on a sampling frame, lottery method was used to group them into two, control and experimental groups. The experimental group was provided with scheduled yoga classes every respective Saturdays.

\section{Sample size}

The total sample size was 60 . The samples were randomly assigned into 30 control group and 30 experimental group for the study purposes. Sample size was determined by appropriate review of the literature and power analysis was used for the calculation of the sample size.

The formula suggested was:

$\mathrm{Z}=\underline{2(\mathrm{Z} \alpha+\mathrm{Z} \beta) 2(\mathrm{P} 55+99)}$

(P1 - P2)

The determined sample size was around 32. The researcher has rounded it by 30 .

\section{Data collection tools and techniques}

The structured questionnaire schedule consists of following sections

- Part-A: Demographic Performa

- Part-B: Infertility characteristics

- Part-C: Fertility problem inventory

- Part-D: Becks depression inventory.

\section{Part-A: Demographic performa}

This was a data sheet for recording the socio-demographic details of each sample. The items included were age, religion, residence, educational status of the women, occupation of the women, family income, and type of family.

\section{Part-B: Infertility characteristics}

Infertility characteristics included age at marriage, married years, history of infertility in years, years of infertility treatment, cause of infertility, no of IVF attempts and number of abortions.

\section{Part-C: Fertility problem inventory}

Dr. Christopher Newton designed Fertility problem inventory to measure the level of stress among the couples suffering from infertility. The scale addresses five major issues common in their life such as social concern, sexual concern, relationship concern, childfree lifestyle and need for parenthood.

Interpretation of the score:

- Social Concern includes all the comments and questions the infertility patient is ought to face and feelings of being isolated from the community, from peers, family, finding social activities very difficult to cope with. 
- $\quad$ Sexual Concern includes loss of interest and pleasure in sexual relations or feelings of pressure due to the treatment related schedule sex and loss of sexual self-esteem individually.

- $\quad$ Relationship Concern includes problems in defining infertility or difficulty in accepting the differences on the basis of gender and concerns about the relationship future.

- Rejection of Childfree Lifestyle includes view on a child free life, and the dependence of happiness on the basis of the birth of the child and perceptional difference in role performance.

- $\quad$ Need For Parenthood include role as a parent, the parenting features, and life goal as a parent.

\section{Scoring}

This scale contains positively phrased items. They are first re keyed as following; $(6=1,5=2,4=3,3=4,2=5,1=6)$. Items: $1,2,6,10$, $12,13,21,25,28,29,30,31,32,33,34,35,36$.

Global Stress/total stress level is calculated as the sum of all the questions.

Interpretation of the score.

\begin{tabular}{|c|c|}
\hline Score & Level \\
\hline$<100$ & Low stress \\
\hline $100-140$ & Average stress \\
\hline $140-180$ & Moderate Stress \\
\hline $180-220$ & Moderately high stress \\
\hline$>220$ & Very High stress \\
\hline
\end{tabular}

Table a

High score

Indicates that the individual is experiencing more psychological stress than the average individual in life.

\section{Part-D: Becks depression inventory}

Aaron T. Beck is the creator of The Beck Depression Inventory. This consists of 21 questions comprising of a self reporting inventory. It's a psychometric test used across the globe for measuring the level of depression.
Every statement is given a number to the right. The total score is interpreted by summing the number right to each response by the sample. The maximum score a sample can obtain is sixty three while the lowest can be till zero. The further evaluation must be done according to the scoring table below.

\begin{tabular}{|c|c|}
\hline Total Score & Levels of Depression \\
\hline $1-10$ & These ups and downs are considered normal \\
$11-16$ & Mild mood disturbance \\
$17-20$ & Borderline clinical depression \\
$21-30$ & Moderate depression \\
Over 30 & Severe depression \\
\hline
\end{tabular}

Table b

Every statement is given a number to the right. The total score is interpreted by summing the number right to each response by the sample. The maximum score a sample can obtain is sixty three while the lowest can be till zero.

\section{Validity and reliability of research tool}

To meet the content validity experts were consulted from various fields and the language was analysed by language experts in Hindi. More than 10 experts did the content validity and 5 experts did the language validity. Necessary changes as mentioned by the experts were made in part A and B of the questionnaire. The demographic variables and infertility characteristics were subjected to test retest method. The ' $r$ ' value obtained was 0.83 (positive correlation). The fertility problem inventory and becks depression scale reliability was established by the owners of the respective tools as the tools are already standardized.

\section{Ethical considerations}

The research proposal was submitted to the ethical committee of Bhopal Memorial Hospital and Research centre. Principal investigator attended the committee meeting and permission was obtained from the same for a period of one year. Written consents were taken from the participants before starting the study. It was ensured by the researcher that the prescribed treatment and routine care of patient will not be affected. Principal investigator assured the confidentiality. The final submission and conclusion were presented before the ethical committee. 


\section{Pilot study}

To assess the feasibility of the study, a pilot study was conducted. The study showed that stress $(\mathrm{p}=0.05)$ and depression $(\mathrm{p}=$ 0.10 ) significantly reduced after the intervention in experimental group. Thus the study concluded that main study can be done on the topic and was feasible. After consulting guide necessary changes were made in the infertility characteristics and the study was progressed to the main study level. The samples selected in the pilot study were excluded in the main study.

\section{Data collection procedure}

The data was collected through questionnaire from women approaching infertility clinic of Bansal hospital and meeting the criteria.

Time period of experimentation: the time period was scheduled as

- Month: April-June (2018)

- Days: Three days per week. Outpatient department with new cases worked on three days Monday, Wednesday and Friday. These days were used to collect samples for the study. Yoga therapy section was Saturday. Every Saturdays other than second Saturdays the experimental group participated in the sessions. Researcher ensured that each participant received 5-6 session before the post test. Thus the minimum gap between the post and pre test was almost 2 months.

Following steps were implemented

- Permission was sought from head of departments to carry out the study.

- $\quad$ The investigator assessed and screened the women attending the Infertility Clinic of Bansal.

- All women meeting the inclusion criteria were selected for the study.

- Subjects were informed of the purpose, objectives and benefits of the study.

- Written consents were obtained from subjects. Full autonomy was given to participate and withdraw at any time.

- $\quad$ The study subjects were randomly assigned to control and experimental group using day randomization (lottery method). Subjects were asked about the willingness to participate in the yoga therapy section. From those who were willing mobile number was collected and informed them that we will follow up. (Follow up was done by the help of what's app group where everyone including the yoga instructor and principal investigator were included. Various motivational messages and posters were used to encourage the participants.) End of the day name of the participants from the sampling frame were noted down in chits and randomly they were sorted using lottery method into both the experimental and control groups.

- After selection of subjects, investigator collected the information regarding demographic data, infertility variables, fertility problem inventory and becks depression scale.

- $\quad$ Pre -test was done in both experimental and control groups each with 30 samples.

- In experimental group intervention was provided and reinforced every week for two months. Individual follow up was done daily basis by what's app messages and information.

- $\quad$ Post test was collected from both the group.

\section{Plan of yoga therapy section}

The entire section was planned and designed by the yoga instructor certified in the area of expertise. The principal investigator took a 3 months class under the yoga instructor to conduct the study and guide the samples.

The whole class maximum of 60 minutes was divided into three main sections focusing on the three main elements of yoga therapy

- Meditation

- Pranayama

- Hatha yoga.

\section{Class pattern}

- Class started with frequent recitation of 'ohm' as mantra (5min)

- Initial breathing exercises to increase the concentration and catch the diverted mind was used.(5 min)

- This was followed by hatha yoga sections and included the basic asanas (20 min).

\section{Suryanamaskar (3 rounds)}

Suryanamaskar or sun salutation is a series of yoga poses that with an immense positive impact on the body and mind. This will help to stay fit, happy and peaceful throughout the day. 


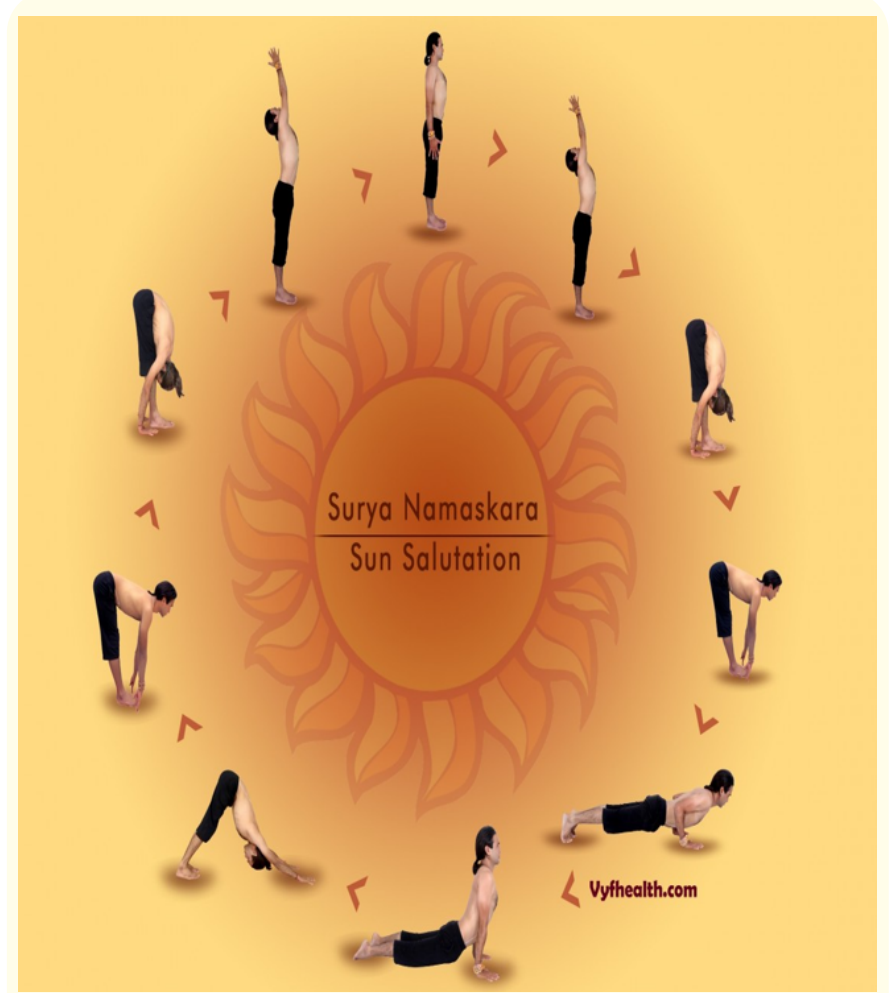

Figure b

Bhiyang asana (cobra pose)

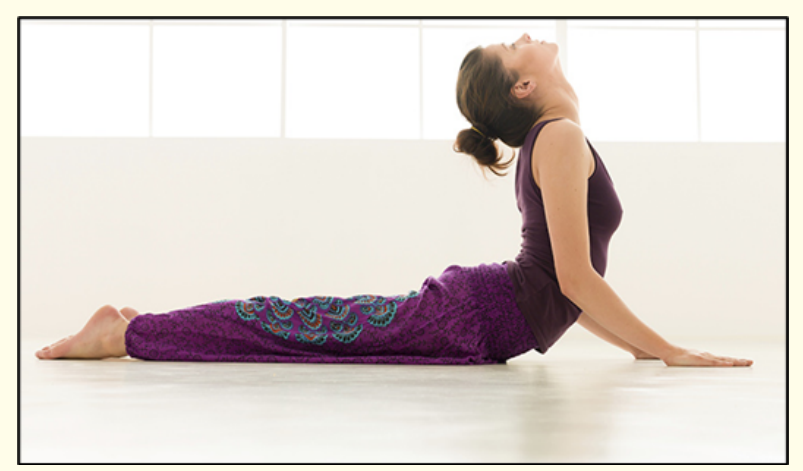

Figure c

This pose does wonders for back pelvis by stimulating hormones and bringing energy to uterus and ovaries. This aids in creating cervical mucus that makes the jouney of sperm easier.
Paschimottasana (seat forward bend pose)

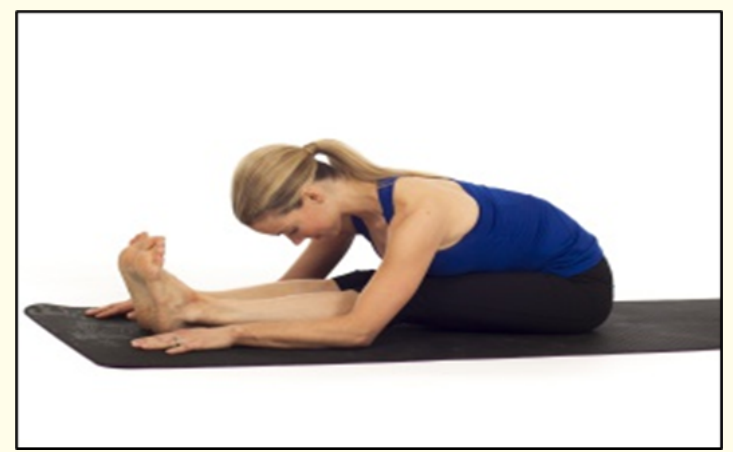

Figure d

This pose is mainly used for the stimulation of endocrine glands, abdominal viscera etc. this pose also stimulates blood flow to the pelvic area. This asana relieves constipation, gastritis, strengthens the muscles of abdomen and removes the sluggishness of liver.

\section{Ushtrasana (camel pose)}

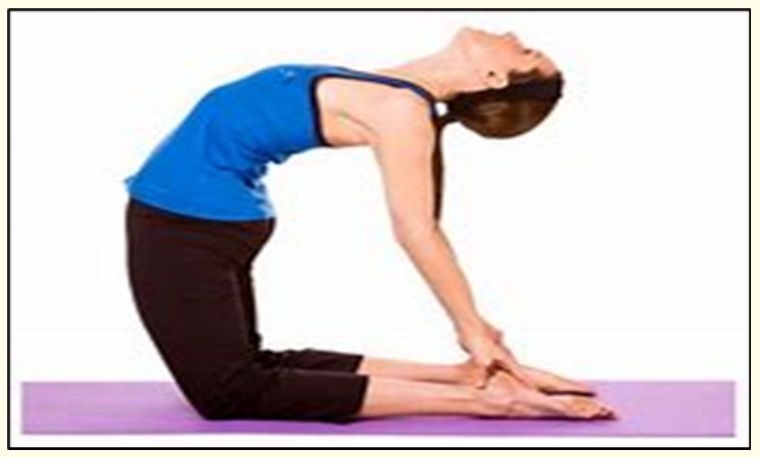

Figure e

Camel pose opens up the hips, stretching deep hip flexors and expands the abdominal region. It also stimulates the nervous system and improves the circulation.

\section{Sethubandhasanaa (bridge pose)}

In this asana, lifting the pelvic region allows energy to circulate to uterus and ovary. This stimulates the thyroid gland. This need to use the buttocks muscle to hold on. This asana treats symptoms like anxiety, stress, depression and fatigue. 


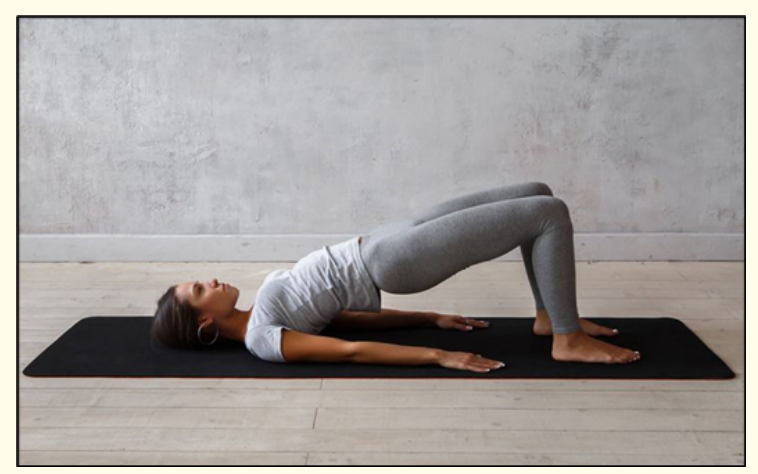

Figure $f$

Poorna tilali asana (butterfly pose)

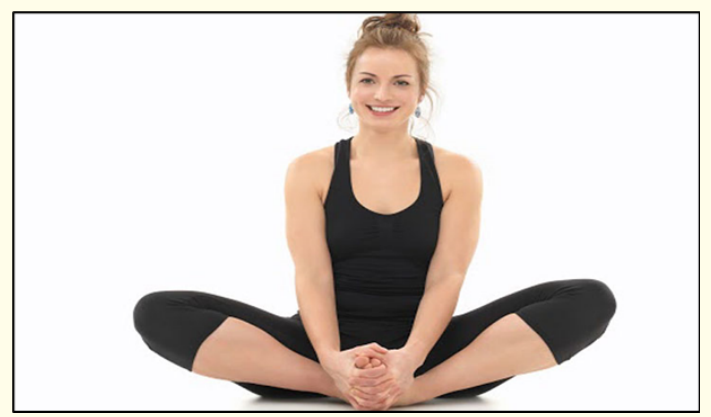

Figure g

This seated pose stimulates the pelvic region. It will carry a tension in hip area thus releasing the negative energy in hip and groin area.

Shavasana (corpse pose)

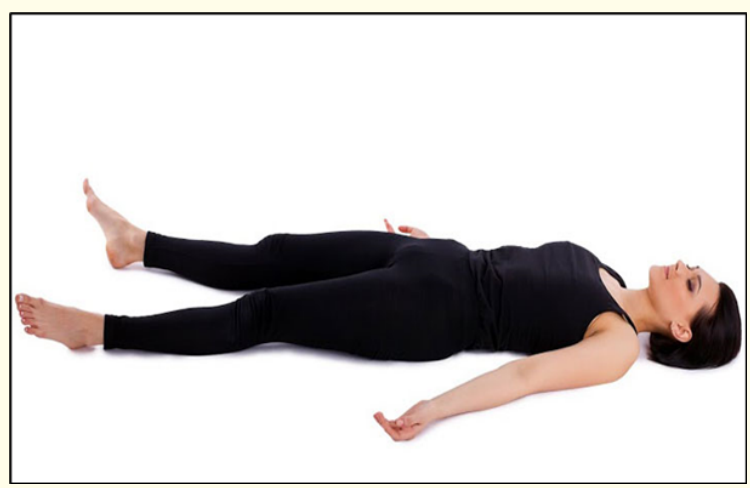

Figure $h$
This relaxes the whole body releasing stress, depression, fatigue and tension. It calms the mind and improves mental health.

The next was pranayam (10 $\mathrm{min})$

- Kapalbathi: This pranayama helps in achieving a good body tone and a better physical state. It soothe your mind and soul.

- Anilom Vilom: It relieves every tension and has healing power of serious health conditions curing depression, asthma, high blood pressure, migrane and arthritis.

- Ujjayi: A focused ujjayi releases tension and strengthens the body as a whole.

- Surya Bhedan: This activates all the body and bodily functions. It destroys all diseases caused by the oxygen insufficiency. It calms the mind.

- Bhramari: This is a great asana for stress relief. This pranayama calms the body and relieves it of stress, anxiety and worry.

Ohm chant and ohm meditation (10 min).

Discussion section (10 $\mathrm{min})$.

\section{Data analysis}

The data was analysed using both descriptive and inferential statistics. Descriptive statistics like percentage, frequency and inferential statistics like paired ' $t$ ' test were applied. Data was analyzed using MS EXCEL and SPSS statistical packages.

\section{Results and Discussion}

Description of demographic data of women undergoing infertility treatment of both control and experimental group.

Table depicts frequency and percentage description as per demographic data sheet. Maximum number of subjects in both the group were between the age group of 21-30 years with $23(76.6 \%)$ in control and experimental group respectively followed by 31-40 years 7 (23.3) in both the groups. None of subjects were above the age of 40years.Hindu religion was the majority in control and experimental groups by $20(66.6 \%)$ and $21(70 \%)$, then Muslims $8(26.6 \%), 7(23.3 \%)$ respectively and Christians $2(6.6)$ in both groups.

As per residential area, 4(13.3\%), 5(16.6\%) were from rural, $10(33.3 \%), 9(30 \%)$ from urban, $6(20 \%), 7(23.3 \%)$ from semi rural 


\begin{tabular}{|c|c|c|c|}
\hline Demographic Variables & Control group $(n=30) f(\%)$ & Experimental group $(n=30) f(\%)$ & p value \\
\hline $\begin{array}{l}\text { Age } \text { in years) } \\
21-30 \text { years } \\
31-40 \text { years } \\
>40 \text { years }\end{array}$ & $\begin{array}{c}23(76.6) \\
7(23.3) \\
0\end{array}$ & $\begin{array}{c}23(76.6) \\
7(23.3) \\
0\end{array}$ & $\mathrm{p}=0.61$ \\
\hline $\begin{array}{l}\text { Religion } \\
\text { Hindu } \\
\text { Muslim } \\
\text { Christian } \\
\text { Others } \\
\end{array}$ & $\begin{array}{c}20(66.6) \\
8(26.6) \\
2(6.6) \\
0\end{array}$ & $\begin{array}{c}21(70) \\
7(23.3) \\
2(6.6) \\
0\end{array}$ & $\mathrm{p}=0.95$ \\
\hline $\begin{array}{l}\text { Residence } \\
\text { Rural } \\
\text { Urban } \\
\text { Semi urban } \\
\text { Semi rural }\end{array}$ & $\begin{array}{c}4(13.3) \\
10(33.3) \\
6(20) \\
10(33.3)\end{array}$ & $\begin{array}{c}5(16.6) \\
9(30) \\
7(23.3) \\
9(30) \\
\end{array}$ & $\mathrm{p}=0.961$ \\
\hline $\begin{array}{l}\text { Educational Status } \\
\text { Primary } \\
\text { secondary } \\
\text { Higher secondary } \\
\text { Graduate and higher }\end{array}$ & $\begin{array}{c}0 \\
4(13.3) \\
9(30) \\
17(56.6)\end{array}$ & $\begin{array}{c}0 \\
5(16.6) \\
11(36.6) \\
14(46.6)\end{array}$ & $\mathrm{p}=0.740$ \\
\hline $\begin{array}{l}\text { Occupation of women } \\
\text { House wife } \\
\text { government job } \\
\text { Private job } \\
\text { Others }\end{array}$ & $\begin{array}{c}18(60) \\
2(6.6) \\
7(23.3) \\
3(10) \\
\end{array}$ & $\begin{array}{l}17(56.6) \\
4(13.3) \\
5(16.6) \\
4(13.3)\end{array}$ & $\mathrm{p}=0.760$ \\
\hline $\begin{array}{l}\text { Family income (per month) } \\
>20,000 \\
20,000-50,000 \\
<50,000\end{array}$ & $\begin{array}{c}2(6.6) \\
12(40) \\
16(53.33) \\
\end{array}$ & $\begin{array}{c}3(10) \\
10(33.3) \\
17(56.6)\end{array}$ & $\mathrm{p}=0.814$ \\
\hline $\begin{array}{l}\text { Type of family } \\
\text { Joint } \\
\text { Nuclear } \\
\text { Extended }\end{array}$ & $\begin{array}{c}17(56.6) \\
13(43.3) \\
0\end{array}$ & $\begin{array}{c}18(60) \\
12(40) \\
0\end{array}$ & $\mathrm{p}=0.500$ \\
\hline
\end{tabular}

Table c

sector and $10(33.3 \%), 9(30 \%)$ from semi urban area respectively in control and experimental group. The educational status of the patients shows that majority of them were graduated evident from $17(56.6 \%)$ in control group and $14(46.6 \%)$ in experimental group. None of them just had a primary level of education.

A good sum of the subjects were housewife's as seen by the status in control group 18(60\%) and experimental group 17(56.6\%). Least number were having a government job 2(6.6\%) in control group and $4(13.3 \%)$ in experimental group Maximum subjects were from a well to do family with family income more than 50,000 in control group 16(53.33\%) and in experimental group
$17(56.6 \%)$. Less than half of the group had an income within the range of 20,000-50,000 in control $12(40 \%)$ and experimental $10(33.3 \%)$ and the minority with income less than 20,000 in both the groups.

As per the type of family, joint family dominated in both the groups with $17(56.6 \%)$ in control and $18(60 \%)$ in experimental group followed by nuclear family. Demographic data of both the groups are statistically comparable in nature.

Description of infertility characteristics of women undergoing infertility treatment of both control and experimental group. 


\begin{tabular}{|c|c|c|c|}
\hline Infertility characteristics & Control group $(n=30) f(\%)$ & Experimental group $(n=30) f(\%)$ & p value \\
\hline $\begin{array}{l}\text { Age at marriage } \\
20-25 \text { years } \\
25-30 \text { years } \\
30-35 \text { years } \\
>35 \text { years. }\end{array}$ & $\begin{array}{c}24(80) \\
6(20) \\
0 \\
0\end{array}$ & $\begin{array}{c}26(86.6) \\
4(13.3) \\
0 \\
0\end{array}$ & $\mathrm{p}=0.365$ \\
\hline $\begin{array}{l}\text { Duration of infertility } \\
<2 \text { years } \\
2-5 \text { years } \\
>5 \text { years }\end{array}$ & $\begin{array}{c}18(60) \\
10(33.3) \\
2(6.6)\end{array}$ & $\begin{array}{c}19(63.3) \\
10(33.3) \\
1(3.33)\end{array}$ & $\mathrm{p}=0.835$ \\
\hline $\begin{array}{l}\text { Type of infertility } \\
\text { Primary } \\
\text { Secondary }\end{array}$ & $\begin{array}{c}30(100) \\
0\end{array}$ & $\begin{array}{c}30(100) \\
0\end{array}$ & \\
\hline $\begin{array}{l}\text { Cause of infertility } \\
\text { Endometriosis } \\
\text { PCOD } \\
\text { Hormonal imbalances } \\
\text { Others }\end{array}$ & $\begin{array}{c}3(10) \\
9(30) \\
5(16.6) \\
13(43.3)\end{array}$ & $\begin{array}{c}5(16.6) \\
11(36.6) \\
4(13.3) \\
10(33.3)\end{array}$ & $\mathrm{p}=0.752$ \\
\hline $\begin{array}{l}\text { Frequency of ART } \\
\text { Number of ovulation induc- } \\
\text { tion } \\
1-3 \\
3-5 \\
\text { Number of IUI } \\
1-3 \\
3-5 \\
\text { Number of IVF } \\
1-3 \\
3-5\end{array}$ & $\begin{array}{c}10(33.3) \\
\\
0 \\
9(30) \\
4(13.3) \\
0\end{array}$ & $\begin{array}{c}14(46.6) \\
2(6.6) \\
3(10) \\
9(30) \\
5(16.6) \\
0\end{array}$ & $\mathrm{p}=0.892$ \\
\hline $\begin{array}{l}\text { History of abortion } \\
\text { Yes } \\
\text { No }\end{array}$ & $\begin{array}{l}12(40) \\
18(60)\end{array}$ & $\begin{array}{l}13(43.3) \\
17(56.6)\end{array}$ & $\mathrm{p}=0.500$ \\
\hline
\end{tabular}

Table d

Table depicts the frequency of infertility characteristics of women undergoing infertility treatment of both control and experimental group.

Age at the time of marriage was between 20 to 25 years for both groups with $24(80 \%)$ In control and $26(86.6 \%)$ in experimental group followed by the age group of $25-30$ years. None of them were married before 20 years and after 30 years.

Duration of infertility was maximum less than 2 years $18(60 \%)$ in control group and $19(63.3 \%)$ in experimental group. One third of the patients were between 2-5 years of duration $10(33.3 \%)$ in both the groups. Least fall into the more than 5 category $2(6.6 \%)$ in control and $1(3.3 \%)$ in experimental group.

As per the type of infertility, all patients were suffering from primary infertility in control and experimental groups (100\%). Causes of infertility were multiple. Polycystic ovary was seen dominating other causes with $9(30 \%)$ in control and $11(36.6 \%)$ in experimental group and then the hormonal imbalances and endometriosis. A significant number felled in the category of others/ idiopathic $13(43.3 \%)$ in control and $10(33.3 \%)$ in experimental 
group. In control group 10(33.3\%) had undergone ovulation induction between 1-3 times and in experimental group 14(46.6\%) had undergone the same for 1-3 times and 2(6.6) for 3-5 times. Intrauterine insemination was performed with $9(30 \%)$ in control group for 3-5 times and experimental group had 3(10\%) for 1-3 times and $9(30 \%)$ for 3-5 times. Control group had $4(13.3 \%)$ were taking In vitro fertilization for 1-3 times whereas experimental group had $5(16.6 \%)$ who were taking the same treatment.

Majority didn't had a history of abortions 18(60\%) in control group and $17(56.6 \%)$ in experimental group while a significant number had a history with $12(40 \%)$ and $13(43.3 \%)$ respectively. Statistically both groups are comparable.

Comparison of pre test stress and depression level among women undergoing infertility treatment of both control and experimental group.

Frequency and percentage distribution of pre-test level of depression among women undergoing infertility treatment of both control and experimental group.

\begin{tabular}{|c|c|c|c|c|c|}
\hline \multirow{2}{*}{ Group } & \multicolumn{5}{|c|}{ Pre test level of Stress } \\
\cline { 2 - 6 } & Low stress (>100) & $\begin{array}{c}\text { Average stress } \\
(\mathbf{1 0 0}-\mathbf{1 4 0 )}\end{array}$ & $\begin{array}{c}\text { Moderate stress } \\
\mathbf{( 1 4 0 - 1 8 0 )}\end{array}$ & $\begin{array}{c}\text { High moderate } \\
\text { stress(180-220) }\end{array}$ & $\begin{array}{c}\text { Very high stress } \\
(\mathbf{1 4 2 0})\end{array}$ \\
\hline Control group $\mathrm{n}=30$ & - & - & $2(6.6 \%)$ & $28(93.3 \%)$ & - \\
\hline Experimental group $\mathrm{n}=30$ & - & - & $4(13.3 \%)$ & $26(86.6)$ & - \\
\hline
\end{tabular}

Table e

Table describes that most of the samples in both control $28(6.6 \%)$ and experimental 26(93.3\%) belonged to high moderate stress and very few fall under moderate stress in control 2(6.6\%) and experimental 4(13.3\%) group.
Frequency and percentage distribution of pre-test level of depression among women undergoing infertility treatment of both control and experimental group.

\begin{tabular}{|c|c|c|c|c|}
\hline \multirow{2}{*}{ Group } & \multicolumn{4}{|c|}{ Pre test level of Depression } \\
\cline { 2 - 5 } & $\begin{array}{c}\text { Mild mood distortion } \\
\mathbf{( > 1 0 )}\end{array}$ & $\begin{array}{c}\text { Borderline Clinical } \\
\text { depression (10-20) }\end{array}$ & $\begin{array}{c}\text { Moderate Depression } \\
(\mathbf{2 0 - 3 0 )}\end{array}$ & $\begin{array}{c}\text { Severe depression } \\
(>\mathbf{3 0})\end{array}$ \\
\hline Control group $\mathrm{n}=30$ & - & - & $14(46.6 \%)$ & $16(53.3 \%)$ \\
\hline Experimental group $\mathrm{n}=30$ & - & - & $13(43.3 \%)$ & $17(56.6 \%)$ \\
\hline
\end{tabular}

Table $\mathbf{f}$

Table describes that most in control group 14 (46.6\%) and in experimental group 13(43.3\%) belonged to moderate depression while $16(53.3 \%)$ in control group and $17(56.6 \%)$ in experimental group suffered from severe depression.

\section{Comparison}

Table compares the mean level of stress and depression in both the experimental and control groups. The mean stress level of the subjects were $184.3+/-3.6$ in control group, however in experimental group it was $184.2+/-4.4$ which is significantly more or the same. Level of depression too showed the same with $30.3+/-2.7 \mathrm{in}$ control group and $30.6+/-3.2$ in experimental group. The calculated ' $\mathrm{t}$ ' value is very less than the tabulate one thus is not significant at 0.05 level of significance

Comparison of post test stress and depression level among women undergoing infertility treatment in experimental and control.

Frequency and percentage distribution of post test stress among women undergoing infertility treatment of both control and experimental group. 


\begin{tabular}{|c|c|c|c|}
\hline Variables & Control group (n= 30) Mean SD & Experimental group (n= 30) Mean SD & ('t' test) level of significance \\
\hline Level of stress & 184.3 & 184.2 & $\mathrm{t}=0.455$ \\
& 3.6 & 4.4 & $\mathrm{p}=\mathrm{NS}$ \\
\hline $\begin{array}{c}\text { Level of } \\
\text { Depression }\end{array}$ & 30.3 & 30.6 & $\mathrm{t}=2.43$ \\
& 2.7 & 3.2 & $\mathrm{p}=\mathrm{NS}$ \\
\hline
\end{tabular}

Table $\mathrm{g}$

NS = Non Significant

\begin{tabular}{|c|c|c|c|c|c|}
\hline \multirow{2}{*}{ Group } & \multicolumn{5}{|c|}{ Post test level of Stress } \\
\cline { 2 - 6 } & $\begin{array}{c}\text { Low stress } \\
(\mathbf{1 0 0 )}\end{array}$ & $\begin{array}{c}\text { Average stress } \\
(\mathbf{1 0 0 - 1 4 0 )}\end{array}$ & $\begin{array}{c}\text { Thoderate stress } \\
(\mathbf{1 4 0 - 1 8 0 )}\end{array}$ & $\begin{array}{c}\text { High moderate stress } \\
(\mathbf{1 8 0 - 2 2 0 )}\end{array}$ & $\begin{array}{c}\text { Very high stress } \\
(\mathbf{2 2 0})\end{array}$ \\
\hline Control group $\mathrm{n}=30$ & - & - & $4(13.3 \%)$ & $26(86.6 \%)$ & - \\
\hline Experimental group $\mathrm{n}=30$ & - & - & $30(100 \%)$ & - & - \\
\hline
\end{tabular}

Table h

Table describes that most of the samples in control 26(86.6\%) falls in high moderate stress add a very few in moderate stress 4 (13.3\%).In experimental group all samples (100\%) falls under moderate stress. This implies a reduction in stress level in experimental group.

Frequency and percentage distribution of post test depression among women undergoing infertility treatment of both control and experimental group.
Table describes that most in control group 15 (50\%) each is present in both the categories of moderate and severe depression while in experimental group majority $23(76.6 \%)$ belonged to borderline clinical depression while a minority $7(23.3 \%)$ fell under moderate depression.

Comparison

Table depicts the efficiency of yoga therapy in comparison with the control group and experimental group.

\begin{tabular}{|c|c|c|c|c|}
\hline \multirow{2}{*}{ Group } & \multicolumn{4}{|c|}{ Post test level of Depression } \\
\cline { 2 - 5 } & $\begin{array}{c}\text { Mild mood distortion } \\
(\mathbf{1 0 )}\end{array}$ & $\begin{array}{c}\text { Borderline Clinical } \\
\text { depression (10-20) }\end{array}$ & $\begin{array}{c}\text { Moderate Depression } \\
\mathbf{( 2 0 - 3 0 )}\end{array}$ & $\begin{array}{c}\text { Severe depression } \\
(\mathbf{3 0 )}\end{array}$ \\
\hline Control group $\mathrm{n}=30$ & - & - & $15(50 \%)$ & $15(50 \%)$ \\
\hline Experimental group $\mathrm{n}=30$ & - & $23(76.6 \%)$ & $7(23.3 \%)$ & - \\
\hline
\end{tabular}

Table i

\begin{tabular}{|c|c|c|c|}
\hline Variables & Control group (n= 30) Mean SD & Experimental group (n= 30) Mean SD & ('t' test) level of significance \\
\hline Level of Stress & 185.0 & 155.9 & $\mathrm{t}=3.005$ \\
& 4.7 & 3.6 & $\mathrm{p}=0.01^{*}$ \\
\hline Level of Depression & 31.4 & 17.8 & $\mathrm{t}=2.43$ \\
& 2.76 & 2.43 & $\mathrm{p}=0.05^{*}$ \\
\hline
\end{tabular}

Table j

$*$ significant 
The level of stress without intervention (post-test) in control group was $185.0+/-4.7$ while in experimental group after intervention was $155.9+/-3.6$ which was significantly lesser than the control group. Depression also had similar result with control group being $31.4+/-2.76$ and experimental group $17.8+/-2.43$ evident variation.

The ' $p$ ' value of stress level was highly significant at 0.01 level of significance and the ' $p$ ' value of depression was significant at a 0.05 level of significance, thus accepting the research hypothesis "There is significant change in the level of stress and depression between pre and post yoga therapy among women undergoing infertility treatment in experimental and control group at 0.05 level of significance.

Association of pre test level of stress and depression with demographic data among women undergoing infertility treatment of both control and experimental group.

Age with pre test stress level among women undergoing infertility treatment of both control and experimental group.

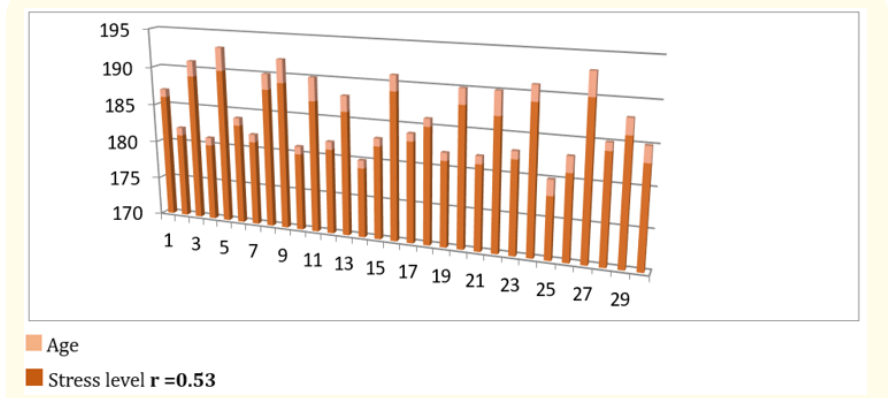

Figure i

Figure depicts the relationship between stress and age, its seen that as the age increases the stress also increased moderately in a positive direction with a correlation coefficient $(r=0.53)$.

Age with pre-test depression level among women undergoing infertility treatment of both control and experimental group.

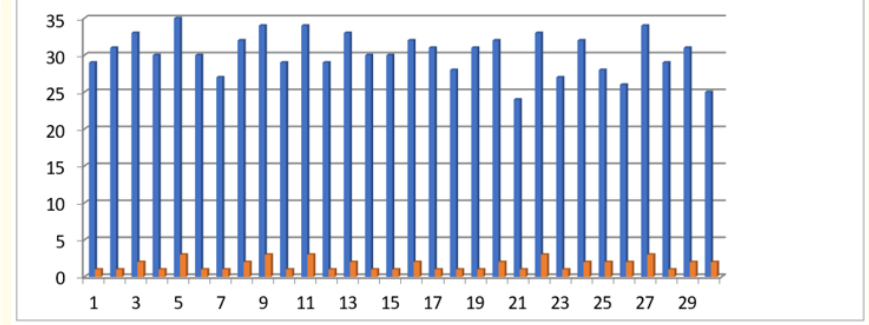

II Depression

Age $\mathbf{r}=\mathbf{0 . 7 3}$

Figure j

Figure depicts the relationship between depression level and age, its seen that as the age increases the depression level also increased. The correlation coefficient $(r=0.73)$ shows a positive relationship between the two variables both the variables are progressing moderately in a positive direction.

Association of pre test stress and depression with infertility characteristics among women undergoing infertility treatment of both control and experimental group.

Duration of infertility (DOI) with pre test stress level among women undergoing infertility treatment of both control and experimental group.

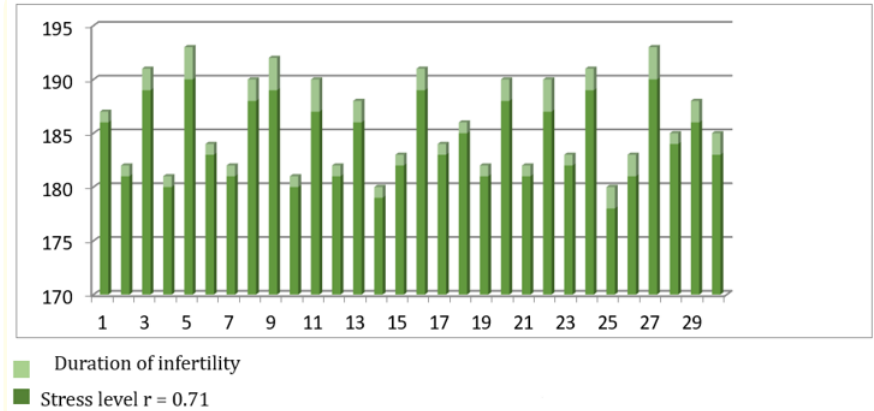

Figure k 
Figure depicts the relationship between stress and duration of infertility, its seen that as the duration of infertility increases the stress also increased moderately in a positive direction $(r=0.71)$.

Duration of infertility (DOI) with pre-test depression level among women undergoing infertility treatment of both control and experimental group.

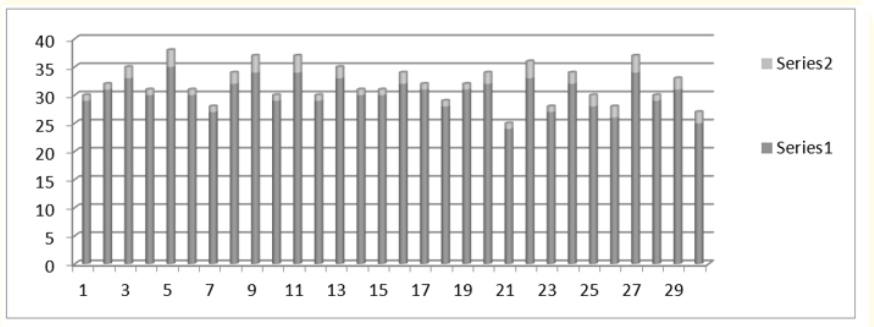

Series 1- Depression Level

Series 2- Duration of Infertility $\mathrm{r}=0.62$.

\section{Figure 1}

Figure depicts the relationship between depression and duration of infertility, its seen that as the duration of infertility increases the depression also increased. The correlation coefficient $(r=0.62)$ shows a positive relationship between the two variables and are progressing moderately in a positive direction.

\section{Discussion}

\section{Description of subjects}

The study was conducted on subjects within the age 20- 45 yrs or above. Maximum number of subjects in both the groups was between the age group 20-30 yrs. Both the control and experimental group had 30 each participant. Hindu religion dominated in control and experimental groups by $20(66.6 \%)$ and $21(70 \%)$, then Muslims $8(26.6 \%), 7(23.3 \%)$ respectively and Christians $2(6.6)$ in both groups. As per residential area, 4(13.3\%), 5(16.6\%) were from rural, 10(33.3\%), 9(30\%) from urban, 6(20\%), 7(23.3\%) from semi rural sector and $10(33.3 \%), 9(30 \%)$ from semi urban area respectively in control and experimental group. The educational status of the patients shows that majority of them were graduated evident from $17(56.6 \%)$ in control group and $14(46.6 \%)$ in experimental group. None of them just had a primary level of education. A good sum of the subjects were housewife's as seen by the status in control group 18(60\%) and experimental group 17(56.6\%). Least number were having a government job $2(6.6 \%)$ in control group and $4(13.3 \%)$ in experimental group Maximum subjects were from a well to do family with family income more than 50,000 in control group $16(53.33 \%)$ and in experimental group $17(56.6 \%)$. Less than half of the group had an income within the range of $20,000-50,000$ in control $12(40 \%)$ and experimental $10(33.3 \%)$ and the minority with income less than 20,000 in both the groups. As per the type of family, joint family dominated in both the groups with $17(56.6 \%)$ in control and $18(60 \%)$ in experimental group followed by nuclear family. Level of significance shows that both the groups are comparable.

\section{Description of infertility characteristics}

Age at the time of marriage was between 20 to 25 years for both groups with $24(80 \%)$ In control and $26(86.6 \%)$ in experimental group followed by the age group of 25-30 years. None of them were married before 20 yrs and after 30 yrs. Duration of infertility was maximum less than 2 years $18(60 \%$ ) in control group and $19(63.3 \%)$ in experimental group. One third of the patients were between $2-5$ years of duration $10(33.3 \%)$ in both the groups. Least fall into the more than 5years category $2(6.6 \%)$ in control and $1(3.3 \%)$ in experimental group. As per the type of infertility, all patients were suffering from primary infertility in control and experimental groups (100\%). Causes of infertility were multiple. Polycystic ovary was seen dominating other causes with $9(30 \%)$ in control and $11(36.6 \%)$ in experimental group and then the hormonal imbalances and endometriosis. A significant number felled in the category of others/idiopathic $13(43.3 \%)$ in control and $10(33.3 \%)$ in experimental group. In control group 10(33.3\%) had undergone ovulation induction between 1-3 times and in experimental group $14(46.6 \%)$ had undergone the same for 1-3 times and 2(6.6) for 3-5 times. Intrauterine insemination was performed with $9(30 \%)$ in control group for 3-5 times and experimental group had 3(10\%) for 1-3 times and 9(30\%) for 3-5 times. Control group had 4(13.3\%) were taking In vitro fertilization for 1-3 times whereas experimental group had 5 (16.6\%) who were taking the same treatment. Majority didn't had a history of abortions $18(60 \%)$ in control group and $17(56.6 \%)$ in experimental group while a significant number had a history with $12(40 \%)$ and $13(43.3 \%)$ respectively. 
Level of significance shows that both the groups are comparable.

\section{Description on stress, depression and yoga therapy}

The study used a combination of three branches of yoga including meditation, pranayama and hata yoga as a psychological adjuvant to women undergoing infertility treatment. In pre-test, the mean stress level of the subjects were $184.3+/-3.6$ in control group, however in experimental group it was $184.2+/-4.4$ which was significantly more or the same. Level of depression too showed the same with $30.3+/-2.7$ in control group and $30.6+/-3.2$ in experimental group. The calculated ' $t$ ' value was very less than the tabulate one thus was not significant at 0.05 level of significance.

In post test, the level of stress without intervention (post-test) in control group was $185.0+/-4.7$ while in experimental group after intervention was $155.9+/-3.6$ which was significantly lesser than the control group. Depression also had similar result with control group being $31.4+/-2.76$ and experimental group 17.8 +/- 2.43 evident variations. The 'p' value of stress level was highly significant at 0.01 level of significance and the ' $p$ ' value of depression was significant at a 0.05 level of significance, thus accepting the research hypothesis

\section{Major findings discussion}

In my study implementing yoga as an interventional method to reduce stress and depression, was found to reduce the same to an extent. This in compliance with the global studies like a randomized study showed that mind body interventions was successful in improving the psychological well being of women undergoing infertility treatment. In a recent study implementing hatha yoga as an adjuvant therapy for the same group, similar results were reported.

In the study it was found that a positive correlation was seen with age and level of stress and depression. The study results that as the age of the participants increased the stress and depression too increased positively. This is in agreement with most of the studies.

Study also found that a positive correlation was seen with duration of infertility and level of stress and depression. This result is in relation with the study of showing the parameters including anxiety increased with duration but a bit contradictory to the study of Sanders (2015) that the stress and depression increases till $1^{\text {st }} 6$ years of infertility and then decreases to a level less than that as the couple adapts to the situation of being infertile.

Study included majority of the patients in the age group of 2030 years. Most belonged to Hindu religion, from different life settings. Among the cause of infertility Polycystic ovarian syndrome was seen as a major cause of infertility which is in relation to various studies like Lund suggesting PCOS as a leading cause of infertility. Measures must be taken from the childhood to prevent PCOS by diet and lifestyle modifications.

\section{Major findings}

- $\quad$ Majority of the patients were within the age group of 20 - 30 yrs.

- Hindu religion dominated among the subjects.

- Polycystic ovarian syndrome was found to be one of the leading causes of infertility.

- Yoga, as an interventional method proved to be effective in reducing the level of stress and depression.

- In the study a positive relation was seen between age and level of stress and depression.

- In the study a positive relation was seen between duration of infertility and level of stress and depression.

- Both the control and experimental groups were comparable in nature.

\section{Conclusion}

The study was conducted to following hypothesis:

- H0: There is no significant change in the level of stress and depression between pre and post yoga therapy among women undergoing infertility treatment in experimental and control group at 0.05 level of significance.

The study found, majority of the patients were within the age group of 20 - 30 yrs. Hindu religion dominated among the subjects. Polycystic ovarian syndrome was found to be one of the leading causes of infertility. Yoga, as an interventional method proved to 
be effective in reducing the level of stress and depression. In the study a positive relation was seen between age and level of stress and depression. In the study a positive relation was seen between duration of infertility and level of stress and depression. Both the control and experimental groups were comparable in nature. Rejecting null hypothesis, the research hypothesis "there is significant change in the level of stress and depression between pre and post yoga therapy among women undergoing infertility treatment in experimental and control group at 0.05 level of significance" was accepted.

\section{Recommendations}

- For further generalization the study must be done in large population

- The study can be done in pregnant women and the effects can be analysed.

- $\quad$ Other type of interventional methods like laughter yoga, humour therapy, imagery, meditation and music therapy etc. can be used instead of yoga.

\section{Limitations}

- $\quad$ Size of the sample was small for generalization of the results.

- Limitation of the study to the patients visiting infertility clinic of Bansal hospital.

\section{Bibliography}

1. Domar AD., et al. "The psychological impact of infertility: A comparison with patients with other medical conditions". Journal of Psychosomatic Obstetrics and Gynecology 14 (2017): 45-52.

2. Leiblum Gameiro S., et al. "Why do patients discontinue fertility treatment? A systematic review of reasons and predictors of discontinuation in fertility treatment". Human Reproduction Update 18 (2012): 652-669.

3. Sanders KA and Bruce NW. "Psychological stress and treatment outcome following assisted reproductive technology". Human Reproduction 14 (2015): 1656-1662.

4. Gnoth Klonoff-Cohen H., et al. "A prospective study of stress among women undergoing in vitro fertilization or gamete intra-fallopian transfer". Fertility and Sterility 76 (2015): 675687.
5. Hardy, Makuch., et al. "Stress and Anxiety Scores in First and Repeat IVF Cycles: A Pilot Study". PLOS ONE 8 (2011): 1-6.

6. Bovin Chiaffarino F., et al. "Prevalence and incidence of depressive and anxious symptoms in couples undergoing assisted reproductive treatment in an Italian infertility department". European Journal of Obstetrics and Gynecology and Reproductive Biology 158 (2017): 235-241.

7. Fathella Hammarberg K., et al. "Women's experience of IVF: a follow up study". Human Reproduction 16 (2012): 374-383.

8. Greil, Broad WJ. "The Science of Yoga: The Risks and The Rewards 1st Simon and Schuster hardcover ed". New York, NY: Simon and Schuster (2017).

9. Yoga in America Study conducted by Yoga Journal and Yoga Alliance reveals growth and benefits of the practice.

10. Carthy MC., et al. "National trends in self reported physical activity and sedentary behaviors among infertile and pregnant women". Preventive Medicine 50 (2014): 123-128.

11. Schmidlt Demyttenaere K., et al. "Coping style and depression level influence outcome in in vitro fertilization". Fertility and Sterility 69 (2015): 1026-1033.

12. Cosine Domar., et al. "A prospective study using Hatha Yoga for stress reduction among women waiting for IVF treatment". Journal of Reproductive and Biomedicine 30 (2014): 542-548.

13. Valoriani V., et al. "Hatha-yoga as a psychological adjuvant for women undergoing IVF: A pilot study". European Journal of Obstetrics and Gynecology and Reproductive Biology 176 (2017): 158-162.

14. Peterson Boivin J., et al. "Tackling burden in ART: an integrated approach for medical staff”. Human Reproduction 27 (2007): 941-950.

15. Moreau Domar AD., et al. "Impact of group psychological interventions on pregnancy rates in infertile women". Fertility and Sterility 73 (2016): 805-812.

16. Coilter Rooney KL., et al. "Impact of a group mind/body intervention on pregnancy rates in IVF patients". Fertility and Sterility (2014): 2269-2273. 
17. Larsen Lin SL., et al. "Effects of yoga on stress, stress adaption and heart rate variability among mental health professionalsA randomized controlled trial". Worldviews on Evidence-Based Nursing (2015): 236-245.

18. Deepak Jindani F., et al. "A yoga intervention for post-traumatic stress: A preliminary randomized control trial". EvidenceBased Complementary and Alternative Medicine (2015): 1-8.

19. Ethan., et al. "Stress and depression in infertility patients". International Journal of Infertility (2016): 34-38.

20. Cook AD and Smith JC. "Stress, relaxation states and creativity. Perception and Motor Skills". Journal of Therapies 88 (2011): 409-416.

21. Brown C., et al. "A randomized comparative trial of yoga and relaxation to reduce stress and anxiety". International Journal of Complementary Therapy 15 (2015): 77-83.

22. Khalsa HK. "Yoga: An adjunct to infertility treatment". Journal of Fertilization 80 (2013): 46-51.

23. Gonth., et al. "Psychological impact of infertility". Best Practice and Research: Clinical Obstetrics and Gynaecology 21 (2015): 293-308.

24. Chen TH., et al. "Prevalence of depressive and anxiety disorders in an assisted reproductive technique clinic". Journal of Human Reproduction (2016): 2313-2318.

25. Lee Galhardo A., et al. "Mindfulness- based workshop for infertility: Efficacy study". Journal of Fertility 100 (2017): 10591067.

26. Mousavi SA., et al. "Assessment of questionnaires measuring quality of life in infertile couples: a systematic review". Journal of Reproductive Infertility 14 (2013): 110-119.

27. Newham JJ., et al. "A fertility problem inventory scores during infertility treatment following intervention with complementary therapies". Journal of Affective Disorders 142 (2012): 2230.

28. Alice Domar., et al. "Manual for the becks depression inventory". Consulting Psychologists Press, Palo Alto, CA (2015): 23-25.
29. Kvaal K., et al. "The Spielberger State-Trait Anxiety Inventory (STAI): the state scale in detecting mental disorders in geriatric patients". International Journal of Psychiatry (2013): 629634.

30. Lim SA and Cheong KJ. "Regular yoga practice improves antioxidant status, immune function, and stress hormone releases in young healthy people: a randomized, double-blind, controlled pilot study". Journal of Alternative and Complementary Medicine (2013): 530-538.

31. Yadav RK., et al. "Efficacy of a short-term yoga based lifestyle intervention in reducing stress and inflammation: Pre-liminary results". Journal of Alternative and Complementary Medicine 18 (2012): 662-667.

32. Batista JC., et al. "Acute and chronic effects of tantric yoga practice and distress index". Journal of Alternative and Complementary Medicine (2015): 1-5.

33. Thirthalli J., et al. "Cortisol and anti-depressant effects of yoga". Indian Journal of Psychiatry 33 (2013): 405-408.

34. Murphy TM., et al. "Anxiety is associated with higher levels of global DNA methylation and altered expression of epigenetic and interleukin-6 genes". Psychiatric Genetics 25 (2012): 7178.

35. Verberg MFG., et al. "Why do couples drop-out from IVF treatment? A prospective cohort study". Human Reproduction. 23 (2014): 2050-2055.

36. Aarts JW., et al. "Relationship between quality of life and distress in infertility: a validation study of the Dutch FertiQoL". Human Reproduction 26 (2011): 1112-1118.

37. Cooper Anderheim L., et al. "Does psychological stress affect the outcome of in vitro fertilization?" Journal of Human Reproduction (2011): 2969-2975.

\section{Volume 3 Issue 6 June 2021}

(C) All rights are reserved by Namitha Josy., et al. 